\title{
Serotonergic dysfunction and aggression control $^{1}$
}

\section{SEROTONIN AND (AUTO) AGGRESSIVE BEHAVIOUR}

\section{Serotonin and depression}

In the early seventies we reported the occurrence of diminished post-probenecid accumulation of 5hydroxyindoleacetic acid (5-HIAA) in cerebrospinal fluid (CSF) in depression (van Praag et al. 1970; van Praag \& Korf, 1971). Lowered baseline and post-probenecid 5-HIAA levels in CSF are an indication of diminished metabolism of the mother amine serotonin (5-hydroxytryptamine, 5HT) in the CNS. Low CSF 5-HIAA appeared not to be related to a particular syndromal depression type, though the phenomenon occurred more frequently in vital (endogenous, melancholic) depression than in personal (neurotic, dysthymic) depression (van Praag et al. 1965); more frequently in severe than in mild depression, and more frequently in psychotic than in non-psychotic depression.

\section{Serotonin and suicide}

In 1976 Asberg et al. confirmed our finding of a low CSF 5-HIAA subgroup in depression and added the important observation that the low 5-HIAA group contained significantly more suicide attempters than the group of depressives with normal CSF 5-HIAA. The risk of repeat suicides was moreover increased in the low 5-HIAA probands (Traskman et al. 1981; Roy et al. 1989). The correlation between low CSF 5-HIAA and attempted suicide was reported to be particularly strong when the attempt had been made with violent means (all methods, except drug overdose and superficial wrist cutting) (Asberg et al. 1984).

The relation between CSF 5-HIAA and suicide appeared to occur not only in depression, but likewise in non-depressed, personality-disordered suicide attempters, though the relation was most pronounced in depressed suicide attempters (Traskman et al. 1981). Low CSF 5-HIAA has also been found in non-depressed schizophrenics who had attempted suicide prompted by commandhallucinations (van Praag, 1983; Ninan et al. 1984). Thus, low CSF 5-HIAA seems to correlate with suicidal behaviour across diagnoses.

Additional arguments for a relation between disturbed 5-HT-ergic functioning and suicidal behaviour were derived from postmortem studies and hormonal challenge tests. In the frontal cortex of individuals who had completed suicide, the number of 5-HT2 receptors was found to be increased (Mann et al. 1986; Arora \& Meltzer, 1989). Hypothetically, this finding can be linked to lowering of CSF 5-HIAA, by assuming that the 5-HT receptor up-regulation is compensatory to decreased 5-HT availability. Hormonal challenge tests also suggest a hyperactive 5-HT. receptor system. M-chlorophenylpiperazine (MCPP), a relatively selective and direct 5-HT1, and 5-HT2 receptor agonist, induced a greater cortisol response in suicide attempters, across diagnoses, compared to non-suicidal depressed patients and normal controls (Korn et al. 1989). Similar findings were reported using 5-hydroxytryptophan as a challenger (Meltzer et al. 1984). Using racemic D,L-fenfluramine - a 5-HT releasing and uptake inhibiting agent - as a challenger, and prolactin release as a 5-HT dependent variable, Coccaro et al. (1989) found evidence for reduced central 5-HT-ergic function in suicide attempters. Racemic fenfluramine, however, is not a selective 5-HT agent. The D-isomer is, but the L-isomer increases dopamine (DA) availability in a selective

\footnotetext{
' Address for correspondence: Dr Herman M. van Praag, Department of Psychiatry, Albert Einstein College of Medicine, Montefiore Medical Center, 1300 Morris Park Avenue, Bronx, New York, NY 10461, USA.
} 
manner (Invernizzi et al. 1986). Hence, blunting of the prolactin response to racemic fenfluramine can be attributed to either decreased 5-HT-ergic activity or increased DA-ergic activity. DA-ergic disturbances have indeed been implicated in suicidal behaviour (Asberg et al. 1984).

\section{Serotonin and aggression}

Abundant data indicate a strong correlation between inward (suicide)- and outward-directed aggression. We have postulated a common disturbance of regulatory mechanisms in both behaviours and accessory factors determining the direction of the aggression (Plutchik et al. 1989a). In accordance with this view, low CSF 5-HIAA was shown to correlate not only with inward, but also with outward-directed aggression in a variety of personality disorders (Roy \& Linnoila, 1988). No negative reports have so far been published. This is surprising, since aggressive behaviour is impacted upon by so many social and toxicological (e.g. alcohol) variables for which it is hard to control. That the 5-HT/aggression correlation seems to hold in spite of that 'noise', suggests it to be quite robust. In normals, too, a correlation has been established between CSF 5-HIAA and levels of hostility (Roy et al. 1988).

\section{Conclusion}

Signs of disturbed 5-HT metabolism, in particular lowered CSF 5-HIAA, initially linked to depression, seem to correlate with disturbances in aggression regulation, irrespective of the direction the aggression takes, and irrespective of the diagnosis in which it occurs.

\section{NEGATIVE STUDIES}

The correlation between suicidal behaviour and lowered CSF 5-HIAA has been confirmed by several, but not by all authors (van Praag, 1986a). What factors could explain the negative findings?

\section{Generalizations}

One explanation is that in biological suicide research, suicidal behaviour is not further categorized. Recent suicide attempt, lifetime history of suicide attempts and suicidal thoughts are being equalized. This generalization is not warranted (van Praag, 1986b). We found that low CSF 5 HIAA correlates with suicide attempt, not with suicidal ideation, and that this correlation is most pronounced in recent suicide attempt (that is, commited one to two weeks before the biological examination).

\section{Depression}

A second possible explanation is that most biological suicide studies do not account for preceding depressions. We demonstrated first of all that in the great majority of suicide attempters, the actual attempt is preceded by depressive symptoms, varying in duration from days to months (van Praag, 1982). In addition, we found that in the days after the attempt, the depressive symptoms tend to clear (van Praag \& Plutchik, 1985). It is conceivable that this mood change is accompanied by a rise in CSF 5-HIAA levels.

\section{Disparity of suicide method and suicide intent}

Several authors failed to replicate the finding that CSF 5-HIAA is lowest in violent attempts. In biological suicide research the term 'violent' refers to suicide method, and by inference to severity of suicidal intent. This inference we demonstrated to be fallacious. Having developed rating scales to measure violence (lethality) independently of the suicide method and severity of the suicide intent, it appeared that these variables do not correlate to a significant degree (Plutchik et al. 1988 $b$ ). Severity of method is no gauge of the strength of the self-destructive impulses. Low CSF 5-HIAA were found to correlate with severity of intent, not with the severity of the attempt. 
This observation makes sense. 5-HT disturbances allegedly correlate with disturbed aggression regulation. The strength of the will to die is an immediate expression of the degree to which that regulation is disrupted. The violence of the method is not. It might have some relation, but the suicide method chosen is co-determined by various other factors, such as availability of a method (e.g. firearms), personality structure (e.g. antisocial personality disorder), gender (violent methods are used more frequently by men), and cultural background (e.g. gunshot used to be the preferred method of suicide among German officers).

Being only peripherally related to suicide intent, it comes as no surprise that the relation between low CSF 5-HIAA and violence of method is variable and unpredictable.

\section{THE BEHAVIOURAL CORRELATION OF THE 5-HT DISTURBANCES}

The 5-HT disturbances found in states of increased (auto)aggression have been linked directly to perturbed aggression regulation. It is conceivable, however, that the primary relation is with another behavioural dimension and that the relation with aggression is secondary. This possibility has not been excluded, and two alternative correlates have to be considered: anxiety and lack of impulse control.

\section{Anxiety}

In anxiety, the same 5-HT dysfunctions have been found as in aggression disorders. In depression, CSF 5-HIAA and anxiety have been reported to be negatively correlated (van Praag, 1988). In panic disorder, moreover, challenge tests with M-chlorophenylpiperazine revealed behavioural and hormonal signs of postsynaptic 5-HT receptor hypersensitivity (Kahn et al. 1988a, b). High doses of MCPP, moreover, provoke anxiety in normal individuals as well (Charney et al. 1987). The fact that drugs that inhibit (presynaptic) 5-HT1A, 5-HT2 or 5-HT3 receptors reportedly possess anxiolytic properties also speaks in favour of a relation between 5-HT and anxiety.

On a behavioural level, anxiety and aggression are also intertwined. Preceding a suicide attempt, anxiety is often severe and can assume panic proportions. In panic disorder, moreover, the suicide rate is increased (Weismann et al. 1989) and so are signs of outward-directed aggression (Korn et al. 1990). In a group of patients from various diagnostic categories, we found trait anxiety to be strongly correlated with both outward- and inward-directed aggression (Apter et al. 1990).

Anxiety and aggression could each relate independently to the 5-HT dysfunction or, alternatively, anxiety is the primary behavioural correlate and the relation 5-HT/aggression its derivative.

\section{Impulse control}

The hypothesis that the 5-HT disturbances found in aggression disturbances are really linked to deficient impulse control would gain in probability if (1) 5-HT disturbances were to be more frequent in impulsive than in premeditated acts of (auto)aggression and (2) the same 5-HT disturbances reported in aggression disorders occurred in other disorders of impulse control. In animals Soubrie (1986), found evidence that 5-HT-ergic neurons enable the organism to tolerate delay before acting to obtain an anticipated reward.

The findings of Linnoila and his group suggest that the first condition is fulfilled (Linnoila et al. 1983; Virkkunen et al. 1989). CSF 5-HIAA was lowest in impulsive violent offenders. Prolactin and cortisol response to fenfluramine were found to be positively correlated to aggressivity and impulsivity in a group of substance abusers (Fishbein et al. 1989). These data, however, are not yet to be taken as definitive. First, information provided by the perpetrator is not necessarily valid. A tendency to accentuate impulsivity is likely because premeditated acts of aggression are taken more seriously, both by the public and the judicature. Moreover, premeditation and impulsivity are endpoints of a dimension. Most aggressive acts fall in between the extremes and can only be wrenched towards either pole.

Data regarding the second condition are few and equivocal. Low CSF 5-HIAA has been observed 
in impulsive arsonists (Virkkunen et al. 1987, 1989), but not in compulsive gamblers (Roy et al. 1988) or in bulimia (Korn et al. 1989). The hypothesis of 5-HT being involved in impulse control rather than in aggression regulation per se lacks firm support so far.

\section{CONCLUSIONS}

I. The evidence suggesting a relationship between diminished 5-HT metabolism and disturbed aggression regulation seems quite strong.

2. The correlation between low CSF 5-HIAA and suicidality is strongest in recent suicide attempts and in depressed suicide attempters. Pre-suicidal depression tends to clear after the act. Disregarding these variables may account for the negative reports that have also appeared.

3. Violence of the suicide method is not a measure for the strength of the suicide intent. In biological suicide research, the term 'violent' refers to suicide method, but low CSF 5-HIAA relates more strongly to suicide intent than to suicide method. Failing to acknowledge that differential relationship may account for the negative reports on violence being a factor strengthening the correlation between low CSF 5-HIAA and suicide.

4. In states of increased anxiety 5-HT disturbances have been found similar to those described in aggressive behaviour. Anxiety and aggression are moreover strongly correlated. It is unclear whether anxiety and aggression relate each independently to 5-HT dysfunctions, or whether the 5$\mathrm{HT} /$ anxiety correlation is primary and the 5 -HT/aggression correlation its derivative.

5. Impulse control is a fundamental psychological function, and failure of that system might underlie overt aggression. It has been suggested that the 5-HT disturbances found in aggression are actually related to defects in impulse control, but the data are so far equivocal.

6. The relationship between 5-HT disturbances and aggression regulation, across diagnoses, is likely to have prophylactic and therapeutic consequences that have as yet been hardly explored. Two small studies found the 5-HT precursor tryptophan to diminish aggressive behaviour in chronic schizophrenics (Morand et al. 1983; Volavka et al. 1990). The anti-aggressive effect of lithium is possibly 5-HT-related. The selective 5-HT uptake inhibitors have yet to be studied in aggression disorders. A group of selective antagonists and agonists of particular 5-HT receptor subtypes is being developed, and some of them have strong anti-aggressive effect in animals. The effect of these so-called 'serenics' (Olivier et al. 1986) in humans is not yet known.

HERMAN M. VAN PRAAG

\section{REFERENCES}

Apter, A., van Praag, H. M., Plutchik, R., Sevy, S., Korn, M. \& Brown, S.-L. (1990). Interrelationship between anxiety, aggression, impulsivity and mood. A possible serotonergically-linked cluster. Psychiatry Research (in the press).

Arora, R. C. \& Meltzer, H. Y. (1989). Serotonergic measures in the brains of suicide victims : 5 -HT2 binding sites in the frontal cortex of suicide victims and control subjects. American Journal of Psychiatry 146, 730-776.

Asberg, M., Traskman, L. \& Thoren, P. (1976). 5-HIAA in the cerebrospinal fluid: a biochemical suicide predictor? Archives of General Psychiatry 33, 1193-1197.

Asberg, M., Bertilsson, L., Matensson, B., Scalia-Tombia, G.-P., Thoren, P. \& Traskman, L. (1984). CSF monoamine metabolites in melancholia. Acta Psychiatrica Scandinavica 69, 201-210.

Charney, D. S., Wood, S. W. \& Henninger, J. R. (1987). Serotonin functions in anxiety. II. Effects of the serotonin agonist MCPP in panic disorder patients and healthy subjects. Psychopharmacology 92, 14-24.

Coccaro, E. F., Siever, L. J., Klar, H. M., Maurer, G., Cochrane, K., Cooper, T. B., Mohs, R. C. \& Davis, K. L. (1989). Serotonergic studies in patients with affective and personality disorders. Archives of General Psy'chiatry 46, 587-599.
Fishbein, D. H., Lozovsky, D. \& Jaffe, J. H. (1989). Impulsivity, aggression, and neuroendocrine responses to serotonergic stimulation in substance abusers. Biological Psychiatry 25, 1049. 1066.

Invernizzi, R., Berettera, C., Garattini, S. \& Samanin, R. (1986). Dand $\mathrm{L}$-isomers of fenfluramine differ markedly in their interaction with brain serotonin and catecholamines in the rat. European Journal of Pharmacology 120, 9-15.

Kahn, R., Wetzler, S., van Praag, H. M. \& Asnis, G. M. (1988 a) Behavioral indications of serotonin receptor hypersensitivity in panic disorder. Psychiatry Research 25, 101-104.

Kahn, R., Wetzler, S., van Praag, H. M. \& Asnis, G. M. (1988b). Neuroendocrine evidence for 5-HT receptor hypersensivity in patients with panic disorder. Psychopharmacology 96, 360 364.

Korn, M., Brown, S.-L. \& van Praag, H. M. (1989), Serolonergic disturbances in suicide. Paper read at the World Congress of Psychiatry, Athens (in the press).

Korn, M. L., Kotler, M., Molcho, A., Grosz, D., Brown, S.-L., Chen, C. \& van Praag, H. M. (1990). Suicide and aggression associated with panic attacks. Biological Psychiatry (submitted).

Linnoila, M., Virkhunen, M., Scheinin, M., Nuutila, A., Rimon, R. \& Goodwin, F. K. (1983). Low cerebrospinal fluid Shydroxyindoleacetic acid concentration differentiates impulsive from non-impulsive violent behavior. Life Sciences 33, 2609 .2614.

Mann, J. J., Stanley, M., McBride, A. \& McEwen, B. S. (1986). 
Increased serotonin, and $\beta$-adrenergic receptor binding in the frontal cortices of suicide victims. Archives of General Psychiatry 43. 954959.

Melt/er. H. Y.. Perline, R., Tricou, B. J., Lowy, M. T. \& Robertson, A. (1984). Effect of 5-hydroxytryptophan on serum cortisol levels in major affective disorders. Il. Relations to suicide, psychosis, and depressive symptoms. Archives of General Psychiatry 41, 379387.

Morind, C., Young, J. N. \& Ervin. F. R. (1983). Clinical response of aggressive schizophrenics to oral tryptophan. Biological Psichiatry 18.575578 .

Ninan. P. T., van Kammen, D. P., Scheinin, M., Linnoila, M., Bunney, W. E.\&Goodwin, F. K.(1984).CSF 5-hydroxyindoleacetic acid levels in suicidal schizophrenic patients. American Journal of Psichiatry 141, 566569

Olivier. B., van Dalen, D. \& Hartog. J. (1986). A new class of psychotropic drugs: serenics. Drugs of the Fufure 11, 473494.

Plutchik, R., van Praag, H. M. \& Conte, H. R. (1989a). Correlates of suicide and violence risk. III. A two-stage model of countervailing forces. Psychiatry Research 28, 215225.

Plutchik, R., van Praag. H. M., Picard. S. Conte, H. R. \& Korn, M. $(1989 h)$. Is there a relation between seriousness of suicide intent and the lethality of the suicide attempt? Psychiatry Research 27, 7179.

Roy, A. \& Linnoila, M. (1988). Suicidal behavior, impulsiveness and serotonin. Acta Psychiarica Scandinavica 78. 529535.

Roy. A.. Adinoff. B. \& Linnoila. M. (1988). Acting out hostility in normal volunteers: negative correlation with levels of 5-HIAA in cercbral spinal fluid. Psychiatry Research 24, 187-194.

Roy, A., Adinoff. B. Rochrich, L., Lamparski, D., Custer, R., Lorenz, V., Barbaccia, M., Guidotti, A., Costa, E. \& Linnoila, M (1988). Pathological gambling. Archives of General Psychiarry 45, 369373.

Roy, A., DeJong, J. \& Linnoila, M. (1989). Cerebrospinal fluid monoamine metabolites and suicidal behavior in depressed piltients. Archives of General Psychiatry 46, 609-612.

Soubrie. P. (1986). Reconciling the role of central serotonin neurons in human and animal behavior. Behavioral and Brain Sciences 9 , 319363

Traskman. L.. Asberg, M.. Bertilsson, L. \& Sjostrand, L. (1981).
Monoamine metabolites in CSF and suicidal behavior. Archives of General Psychiatry 38, 631 636

van Praag, H. M. (1982). Depression, suicide and the metabolism of serotonin in the brain. Journal of Affective Disorders 4, 275290.

van Praag, H. M. (1983). CSF 5-HIAA and suicide in non-depressed schizophrenics. Lancet i, 977-978.

van Praag, H. M. (1986a). (Auto)aggression and CSF 5-HIAA in depression and schizophrenia. Psychopharmacology Bulletin 22, 669-673.

van Praag, H. M. (1986h). Biological suicide research: outcome and limitations. Biological Psychiary 21, 13051323.

van Praag, H.M. (1988). Serotonergic mechanisms and suicidal behaviour. Psychiatry and Psychohiology 3, 335346.

van Praag, H. M. \& Korf, J. (1971). Endogenous depressions with and without disturbances in the 5-hydroxytryptamine metabolism: a biochemical classification? Psychopharmacologia 19, 148152.

van Praag, H. M. \& Plutchik, R. (1985). An empirical study on the 'cathartic effect' of attempted suicide. Psychiatry Rescarch 16, 123130.

van Praag, H. M., Ulemann, A. M. \& Spitz, J. C. (1965). The vital syndrome interview. A structured standard interview for the recognition and registration of the vital depression symptom complex. Psychiarrica Neurologia Neurochirurgia 68, 329346.

van Praag, H. M., Korf, J. \& Puite, J. (1970). 5-hydroxyindoleacetic acid levels in the cerebrospinal fluid of depressive patients treated with probenecid. Nature 225, 1259 - 1260.

Virkkunen, M., Nuttila, A., Goodwin, F. K. \& Linnoila, M. (1987). Cerebrospinal fluid monoamine melabolite levels in male arsonists. Archives of General Psychiatry 44, 241-247.

Virkkunen, M., DeJong, J., Bartko, J. \& Linnoila, M. (1989). Psychobiological concomitants of history of suicide altempts among violent offenders and impulsive fire setters. Archives of General Psychiatry 46, 604-606.

Volavka, J., Crowner, M., Brizer, D., Convit, A., van Praag, H. M. \& Cooper, T. (1990). Tryptophan treatment of aggressive psychiatric patients. Biological Psychiatry (in the press)

Weissman, M. M., Klerman, G. L., Markowitz, J. S. \& Ouellette, R. (1989). Suicidal ideation and suicide attempt in panic disorder and attacks. New' England Journal of Medicine 321, 12091214. 